\title{
Effects of the $\beta_{2}$-adrenoceptor antagonist ICI 118,551 on blood pressure in hypertensive patients known to respond to $\beta_{1}$-adrenoceptor antagonists
}

\author{
O. J. ROBB, J. WEBSTER, J. C. PETRIE, J. D. HARRY ${ }^{1} \&$ J. YOUNG ${ }^{1}$ \\ Clinical Pharmacology Unit, Department of Medicine and Therapeutics, University of Aberdeen, Polwarth \\ Building, Foresterhill, Aberdeen AB9 2ZD and ${ }^{1}$ Clinical Pharmacology Unit, Clinical Research Department \\ ICI plc, Pharmaceuticals Division, Macclesfield, Cheshire SK10 4TG
}

1 The selective $\beta_{2}$-adrenoceptor antagonist ICI $118,551,50 \mathrm{mg}$ orally given thrice daily, did not lower blood pressure in hypertensive patients known to respond to therapy with atenolol or propranolol.

2 This dosage regimen resulted in a small decrease in supine heart rate which might represent partial $\beta_{1}$-adrenoceptor antagonism by ICI 118,551.

3 The results suggest that $\beta_{2}$-selective antagonism does not play a role in the hypotensive action of $\beta$-adrenoceptor antagonists.

Keywords ICI 118,551 $\beta_{2}$-adrenoceptor antagonist hypertension atenolol propranolol

\section{Introduction}

The mechanisms by which $\beta$-adrenoceptor antagonist drugs influence blood pressure in animals and man appear to be complex. Both non-selective and $\beta_{1}$-selective agents have been used in clinical practice to reduce blood pressure in patients with hypertension, suggesting a relative importance of blockade of $\beta_{1}$-adrenoceptors. The effects of predominant blockade of $\beta_{2}$ adrenoceptors on the blood pressure of hypertensive patients appear negligible (Dahlof $e t$ al., 1983), although previously available $\beta_{2^{-}}$ adrenoceptor antagonists may have lacked selectivity (O'Donnell \& Walduck, 1981).

ICI 118,551 ( \pm -erythro-3-isopropylamino1-(7-methyl-4-indanyloxy)-2-butanol hydrochloride) is a selective $\boldsymbol{\beta}_{2}$-adrenoceptor blocking drug which has been shown in animal models to have a selectivity ratio of $\beta_{2}$ over $\beta_{1}$ of at least 200 (Bilski et al., 1983). Selectivity has also been demonstrated in normal man (Fitzgerald $e t$ al., 1982; Tattersfield \& Cragg, 1983; Arnold et al., 1985).

Observations on the effect of ICI 118,551 in hypertensive patients known to respond to cardioselective or non-cardioselective $\beta$-adrenoceptor blocking drugs should give information about the relative contribution of blockade of $\beta_{2^{-}}$ adrenoceptors to the antihypertensive effect of $\beta$-adrenoceptor blocking agents.

\section{Methods}

Subjects

Ten patients (six male, four female, mean age 46 years) with essential hypertension successfully treated with atenolol (8) or propranolol (2) alone were studied. Mean pre-treatment sustained supine blood pressure was $167 / 104 \mathrm{~mm} \mathrm{Hg}$ (s.d. $21 / 8$ ) and on treatment $128 / 81 \mathrm{~mm} \mathrm{Hg}$ (s.d. 21/10). The duration of previous therapy with $\beta$ adrenoceptor blockers ranged from 3-101 (mean 25.4) months. None of the patients had a history of asthma or peripheral vascular disease. The study was approved by the Joint Ethics Committee of Grampian Health Board and the University of Aberdeen. All patients gave informed written consent. 


\section{Design}

All usual therapy was withdrawn and the $\beta$ adrenoceptor blocker replaced by a matching placebo for an initial washout period. Patients remained on placebo for up to 1 month until the supine diastolic blood pressure (Phase 5) had risen to more than $95 \mathrm{~mm} \mathrm{Hg}$. During this washout period the treadmill exercise load required to produce a target heart rate of 140 beats $\min ^{-1}$ at the end of $3 \mathrm{~min}$ was determined.

On entering the active treatment period ICI $118,55150 \mathrm{mg}$ as an oral syrup, or matching placebo were given thrice daily for 1 week according to a double-blind randomised crossover design with washout placebo matching the original $\beta$-adrenoceptor blocker therapy prescribed for the intervening week. After 1 further week of this placebo, patients returned to their pre-study therapy. The patients were studied on 6 separate days: Day 1 and Day 8 of the two randomised treatment periods and on Day 1 and Day 8 following re-institution of pre-study $\beta$-adrenoceptor blocker therapy. Supine, standing end-exercise and post-exercise heart rates and blood pressures were measured before the first (Day 1) and last (Day 8) dose and at 2, 4 and $6 \mathrm{~h}$ post dose on each of these days.

\section{Methods of measurement}

Blood pressure was measured on each of the study days using the previously described Remler semi-automated recording system (Scott \& Petrie, 1982). The mean of two readings was recorded in the supine and standing positions and one reading for end-exercise and $15-30$ s post-exercise. Heart rate was measured from an ECG trace.

\section{Statistical analysis}

Changes from baseline (Day 1 before first treatment in the double-blind treatment phase (time $0)$ ) for any one treatment were analysed for all results. In the comparison of ICI 118,551 and placebo ANOVA preceded a Student's $t$-test. Comparison of placebo and ICI 118,551 with results following re-introduction of usual therapy after a further week on placebo was by a paired Student's $t$-test. Confidence intervals $(95 \%)$ for mean differences from baseline were calculated for supine systolic and diastolic blood pressure and exercise heart rate (Gardner \& Altman, 1986).

\section{Results}

All 10 subjects received placebo, ICI 118,551 and their usual therapy. No untoward effects were recorded in the study.

\section{Heart rates}

ICI 118, 551 vs placebo In the supine position comparison of the differences from baseline (time 0, Day 1) 2, 4 and $6 \mathrm{~h}$ after dosing on Day 1 and before the last dose and 2, 4 and $6 \mathrm{~h}$ after dosing on Day 8 showed a significant reduction in heart rate after ICI 118,551 (Table 1). This did not occur in the standing position, at end-exercise nor post-exercise (except, $2 \mathrm{~h}$ post dosing on Day 1).

ICI 118, 551 vs usual therapy Comparison of the reductions from baseline after dosing on Days 1 and 8 showed these to be significantly greater at all times after usual therapy in the standing position, at end-exercise, and postexercise (Table 1 ). No statistically significant difference was shown in the supine position (except $2 \mathrm{~h}$ post-dosing on Day 8 ) but the heart rates on usual treatment were lower than on ICI $118,551$.

The changes in post-exercise heart rate followplacebo, ICI 118,551 and usual therapy are shown in Figure 1 and show that apart from $2 \mathrm{~h}$ after the first dose of placebo or ICI 118,551, there was no difference from baseline with these treatments whilst with usual treatment there clearly was.

\section{Systolic blood pressure}

Comparison of the difference from baseline after dosing on Days 1 and 8 showed no significant reduction after placebo or ICI 118,551 in supine, standing, end-exercise or post-exercise pressures. A statistically significant increase over baseline was noted after ICI 118,551 in the supine position on Day 8, $2 \mathrm{~h}$ post dosing and in the standing position on three occasions-Day 1 at 2 and $6 \mathrm{~h}$ and Day 8 at $0 \mathrm{~h}$. These effects were small and of the order of $2 \mathrm{~mm} \mathrm{Hg}$ supine and 3-8 $\mathrm{mm} \mathrm{Hg}$ standing.

Comparison of the differences from baseline showed these to be significantly greater after usual therapy compared with ICI 118,551 at all times on Days 1 and 8 in the supine (except Day $1,2 \mathrm{~h}$ ) and standing positions and at end-exercise (except Day 8, $0 \mathrm{~h}$ ).

The effects of placebo, ICI 118,551 and usual therapy on supine systolic blood pressure on Days 1 and 8 are summarised in Figure 2. Clearly there is little difference between ICI 118,551 and placebo and no hint of a reduction in systolic pressure following ICI 118,551. 


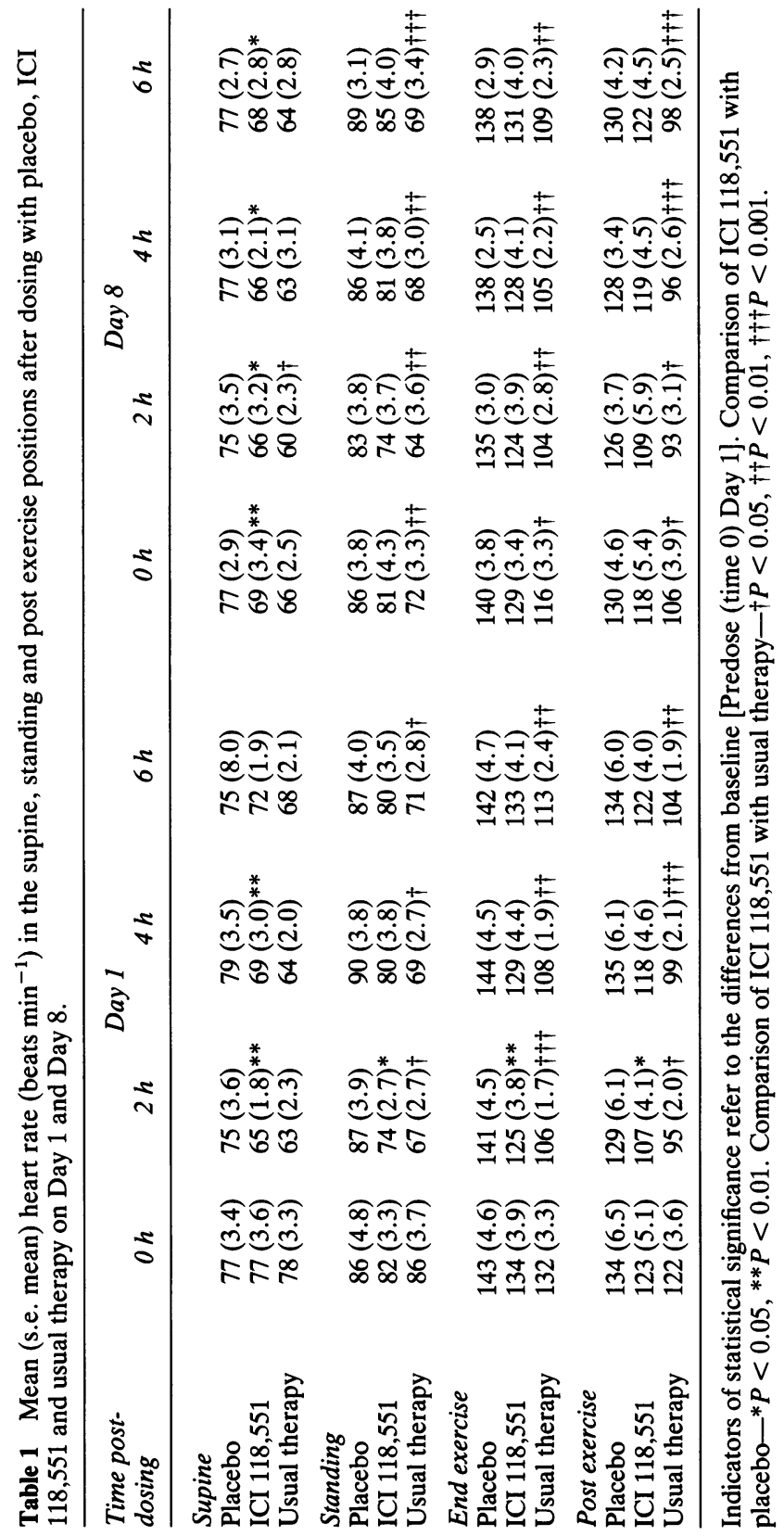




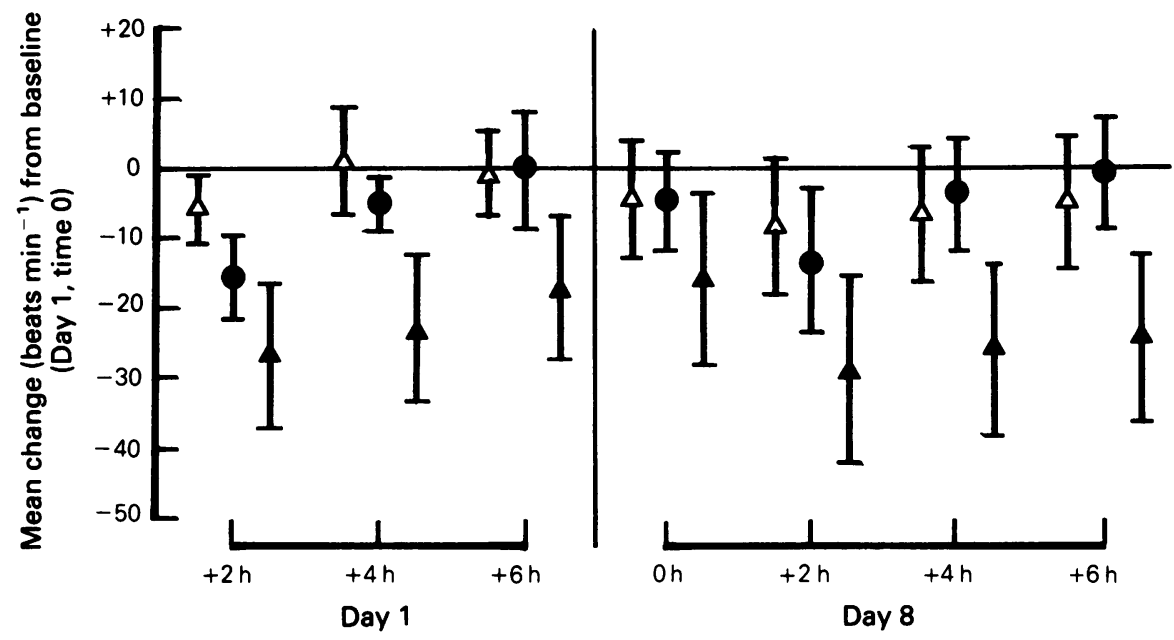

Figure 1 Mean change (beats $\min ^{-1}$ ) from baseline (Day 1, time 0 ) for post exercise heart rate on Days 1 and 8 following placebo $(\Delta), \operatorname{ICI} 118,551(\bullet)$ and usual therapy $(\Delta)$ showing $95 \% \mathrm{CI}, t=2.262$.

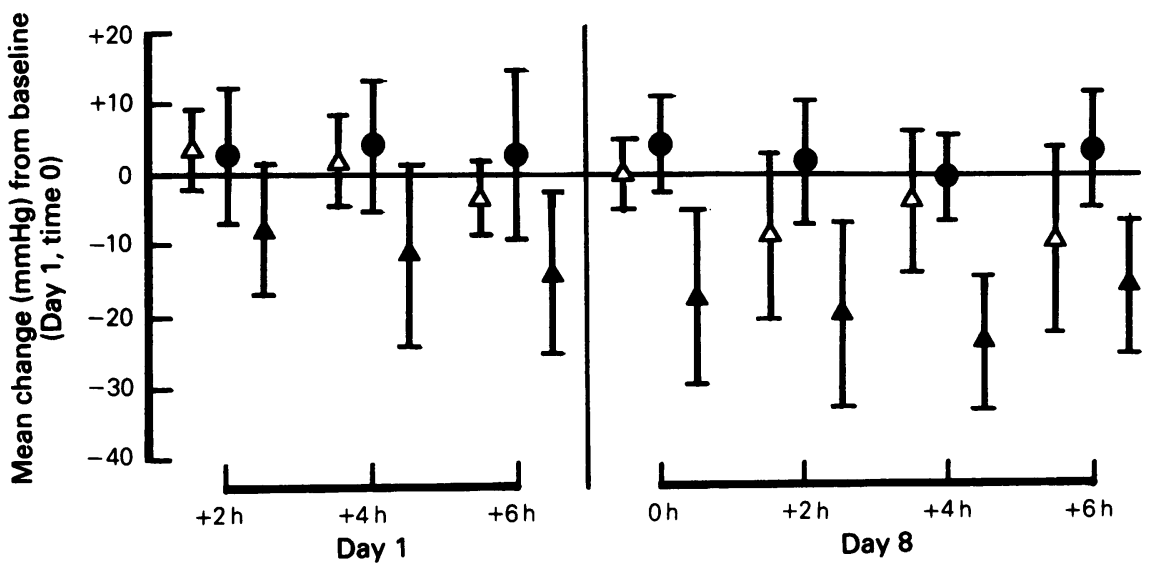

Figure 2 Mean change ( $\mathrm{mm} \mathrm{Hg}$ ) from baseline (Day 1, time 0 ) for supine systolic blood pressure on Days 1 and 8 following placebo $(\Delta)$, ICI 118, $551(\bullet)$ and usual therapy $(\Delta)$ showing $95 \%$ CI, $t=2.262$.

\section{Diastolic blood pressure}

Similar comparisons showed no significant reduction of diastolic blood pressure after ICI 118, 551 compared to placebo in the lying, standing, end-exercise or post-exercise measurements. A significant increase was shown after ICI 118, 551 in the supine position on Day 8 at 0 and $2 \mathrm{~h}$ compared to baseline. The increase was modest and of the order of 4-7 mm Hg. This effect is summarised in Figure 3 which also shows the tendency of ICI 118, 551 to raise supine diastolic pressure compared to placebo and usual therapy at other time points.

\section{Discussion}

The results of this study show that the selective $\beta_{2}$-adrenoceptor antagonist ICI 118,551 given orally in a dose of $50 \mathrm{mg}$ three times daily for 1 week did not reduce to any clinically important 


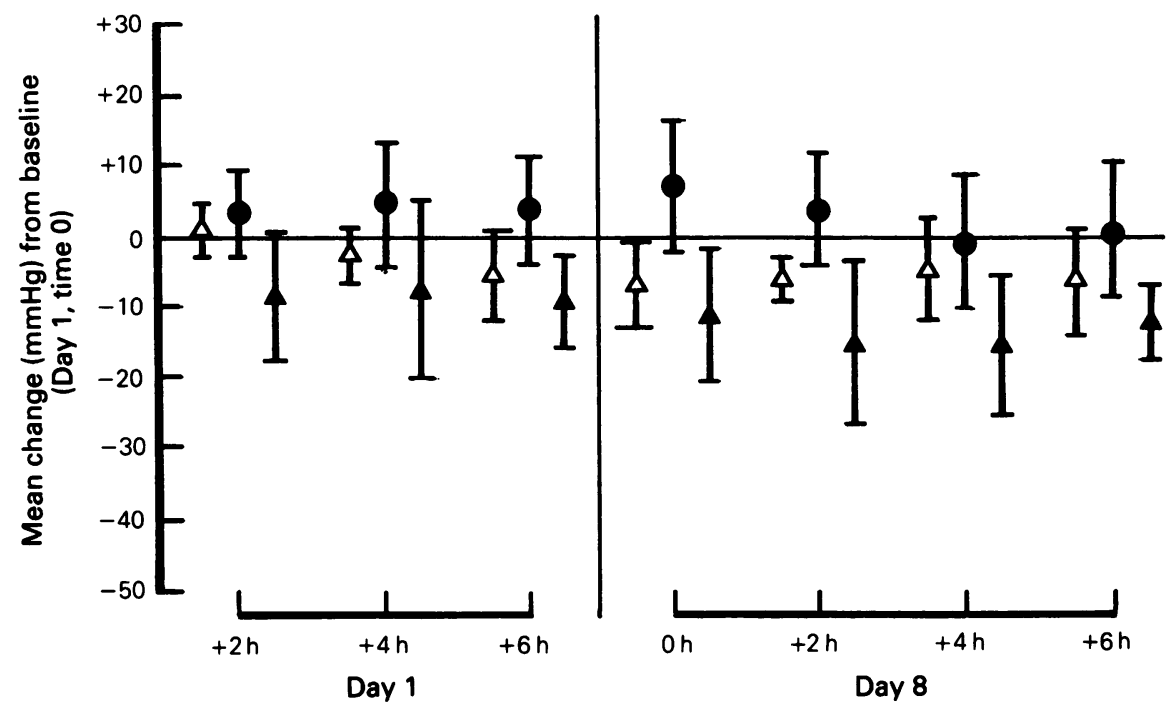

Figure 3 Mean change ( $\mathrm{mm} \mathrm{Hg}$ ) from baseline (Day 1, time 0 ) for supine diastolic blood pressure on Days 1 and 8 following placebo $(\Delta)$, ICI 118,551 (•) and usual therapy $(\Delta)$ showing $95 \% \mathrm{CI}, t=2.262$.

degree the systolic or diastolic blood pressures of patients with hypertension known previously to respond to $\beta$-adrenoceptor antagonists. This suggests that blockade of $\beta_{2}$-adrenoceptors does not contribute to the control of blood pressure when $\beta$-adrenoceptors are used in the treatment of patients with hypertension.

The results on resting blood pressures are in agreement with those reported by Dahlof $e t$ al. (1983) who used rather higher doses than used in our study ( 50 or $100 \mathrm{mg}$ three times daily) and a less stringent design. In both studies the investigations were performed in patients who were known to be responsive to either $\beta_{1}$-selective or non-selective $\beta$-adrenoceptor blocking drugs. The evidence to support the findings in our study resides in the observations that blood pressure rose after withdrawal of usual therapy with the $\beta$-adrenoceptor blocking drugs and fell again when that therapy was re-introduced. The effects of the original therapy on blood pressure were clearly different to those of ICI 118,551 thus making the lack of effect of ICI 118,551 a positive observation.

Four points should be made in respect of the design of our study. Firstly we have previously shown that a 1 week washout period of preexisting $\beta$-adrenoceptor blocker therapy is sufficient (Webster et al., 1982) but a longer interval might have been preferable. Secondly the requirement to demonstrate the effectiveness of preexisting $\beta$-adrenoceptor blocker therapy in individual patients following the double-blind phase of the study led to a potential source of bias in that such therapy always followed the comparison of ICI 118,551 with placebo. Observer bias in this non double-blind period of observation was reduced by use of the Remler semiautomated device which minimises involvement of observers (Scott \& Petrie, 1982). Fourthly, examination of the results and $95 \%$ confidence intervals does not suggest that inclusion of a larger number of patients would have exposed significant differences between ICI 118, 551 and placebo in their effect in reducing blood pressure.

In view of the lack of effect of ICI 118, 551 in this study, at least on blood pressure, it is important to cite evidence that $50 \mathrm{mg}$ does produce blockade of $\beta_{2}$-adrenoceptors in man. Tattersfield \& Cragg (1983) showed in normal volunteers a significant displacement of the bronchial airway dose-response curve to salbutamol comparing this $\beta_{2}$-adrenoceptor antagonism at the bronchi with little (but some) effect on exercise tachycardia both $2 \mathrm{~h}$ after a $50 \mathrm{mg}$ dose of ICI 118,551 . Stimulation of $\beta_{2}$-adrenoceptors by intravenous isoprenaline as shown by a fall in diastolic blood pressure, increase in physiological tremor or fall in serum potassium in man can be antagonised by doses of ICI 118, 551 as low as $5 \mathrm{mg}$ oral dose $2 \mathrm{~h}$ after dosing (Fitzgerald et al., 1982; Arnold et al., 1985; Brown et al., 1983). Some small effects are probably seen on $\beta_{1}$-adrenoceptors at $40-50 \mathrm{mg}$ single oral doses of ICI 118, $5512 \mathrm{~h}$ after dosing (Arnold et al., 1985; Harry et al., 1984). However, in the present 
study the lack of effect of ICI 118, 551 on endexercise heart rate and systolic blood pressure would suggest that this was not occurring. If the doses used in our study had produced some small antagonism on $\beta_{1}$-adrenoceptors some effect should have been evident on blood pressure at least 2 and $4 \mathrm{~h}$ after the last dose of drug on Day 8. The doses did not affect blood pressure and so even if some effect is occurring at $\beta_{1}$-adrenoceptors this clearly was not sufficient to produce any fall in blood pressure in our patients with hypertension.

Two other interesting observations were seen in this study. Firstly the small reduction in heart rate seen in the patients with hypertension are in agreement with the results of Dahlof et al. (1983), but are at variance with results from normal volunteers where doses up to $100 \mathrm{mg}$ do not seem to affect the resting heart rate (Arnold $e t$ al., 1985; Harry et al., 1984). This may reflect a greater sensitivity of the heart in hypertensive patients to $\beta_{1}$-adrenoceptor blockade, or may reflect a relative importance of $\beta_{2}$-adrenoceptors in hypertensive patients compared with normals. $\beta_{2}$-adrenoceptors are present in the human atrium (Brodde et al., 1983) but whether differences exist between hypertensives and normals is not known. In a study in normotensive volun-

\section{References}

Arnold, J. M. O., O'Connor, P. C., Riddell, J. G., Harron, D. W. G., Shanks, R. G. \& McDevitt, D. G. (1985). Effects of the $\beta_{2}$-adrenoceptor antagonists ICI 118, 551 on exercise tachycardia and isoprenaline induced $\beta$-adrenoceptor responses in man. Br. J. clin. Pharmac., 19, 619-630.

Bilski, A. J., Halliday, S. E., Fitzgerald, J. D. \& Wale, J. L. (1983). The pharmacology of a $\beta_{2}$-selective adrenoceptor antagonist (ICI 118, 551). J. cardiovasc. Pharmac., 5, 430-437.

Brodde, O. E., Karad, K., Zerkowski, H. R., Rohm, N. \& Reidemeister, J. C. (1983). Coexistence of $\beta_{1}-\beta_{2}$ adrenoceptors in human right atrium. Direct identification by I-(125) iodocyanopindolol binding. Circ. Res., 53, 752-758.

Brown, M. J., Brown, D. C. \& Murphy, M. B. (1983). Hypokalaemia from $\beta_{2}$-receptor stimulation by circulating epinephrine. New Engl. J. Med., 309, 1414-1419.

Dahlof, B., Andren, L., Svensson, A. \& Hanssen, L. (1983). Antihypertensive mechanism of $\beta$ adrenoceptor antagonism - the role of $\beta_{2}$-blockade. J. Hypertension, 1 (Suppl 2), 112-115.

Daule, A., Johnston, T., Reher, M., Kruger, M. \& Brodde, O-E. (1986). Abstracts of 11th Scientific Meeting of the International Society of Hypertension, 128P.

Fitzgerald, D., Gumbrielle, J. \& Harry, J. D. (1982). Effects in man of ICI 118, 551 (a selective $\beta_{2^{-}}$ teers (Daule et al. , 1986) ICI 118, 551 in a dose of $25 \mathrm{mg}$ three times a day for 14 days inhibited isoprenaline-induced tachycardia and fall in diastolic blood pressure (mediated principally via $\beta_{2}$-receptors) but had no effect on exercise induced tachycardia (mediated principally via $\beta_{1^{-}}$ receptors). On vigorous exercise a difference appears to exist because $\boldsymbol{\beta}_{2}$-adrenoceptor blockade clearly does not affect the tachycardia or the systolic blood pressure response.

Secondly ICI 118, 551 may have produced a small rise in diastolic blood pressure in the hypertensive patients both at rest and on exercise (maximal effect about $6 \mathrm{~mm} \mathrm{Hg}$ in the supine position). A similar trend has been seen in studies in normal volunteers (Arnold et al., 1985; Harry et al., 1984). The mechanism of this small rise in diastolic blood pressure may be related to the activity of circulating adrenaline. The latter can produce vasodilatation of blood vessels in skeletal muscle by stimulation of $\beta$-adrenoceptors. ICI 118,551 can block the effect of circulating adrenaline and so increase peripheral resistance.

We would like to acknowledge the help received from Mr Steve Cook, Data Section, Clinical Research Department, ICI PLC (Pharmaceuticals Division) in the statistical analysis of our data.

adrenoceptor blocking drug) on some cardiovascular responses induced by isoprenaline. Br. J. clin. Pharmac., 13, 586P.

Gardner, M. J. \& Altman, D. G. (1986). Confidence intervals rather than $\mathrm{p}$ values: estimations rather than hypothesis testing. Br. med. J., 292, 746-750.

Harry, J. D., Norris, S. C., Percival, P. G. \& Young, J. (1984). Effects in man of ICI 118, 551 (a $\beta_{2^{-}}$ adrenoceptor antagonist) on some cardiovascular actions of dobutamine. Br. J. clin. Pharmac., 17, 187P-188P.

O'Donnell, S. R. \& Walduck, K. (1981). How $\beta_{2-}$ selective is the adrenoceptor antagonist drug IPS 339? J. Pharm. Pharmac., 33, 223-225.

Scott, A. K. \& Petrie, J. C. (1982). Assessment of Remler blood pressure recording system. Br. J. clin. Pharmac., 13, 289P-290P.

Tattersfield, A. E. \& Cragg, D. J. (1983). Effect of ICI 118,551 on brohchial $\beta$-adrenoceptor function and exercise heart rate in normal man. Br. J. clin. Pharmac., 16, 587-590.

Webster, J., Hawksworth, G. M., Barber, H. E., Jeffers, T. A. \& Petrie, J. C. (1982). Withdrawal of long-term atenolol in hypertensive patients. $B r . J$. clin. Pharmac., 12, 211-214.

(Received 21 October 1986, accepted 10 December 1987) 